\title{
Improvement the impact damage resistance of composite materials by interleaving Polycaprolactone nanofibers
}

\author{
H. Saghafi*, T. Brugo, G. Minak, and A. Zucchelli
}

\begin{tabular}{l} 
Department of Industrial Engineering (DI \\
\hline A R T I C L E I N F O \\
\hline Article history: \\
Received September 6, 2014 \\
Accepted 22 November 2014 \\
Available online \\
23 December 2014 \\
\hline Keywords: \\
Nanofibers \\
Electrospinning \\
Impact loading \\
Interleaving
\end{tabular}
\begin{abstract}
A B S T R A C T
In this study, the impact response of glass/epoxy laminates interleaved by Polycaprolactone (PCL) nanofibers is considered. PCL is a thermoplastic polymer, which is a good choice for toughening epoxy-based composite. The impact tests were conducted on curved laminates and under 24 and 36J. The results showed that the effect of interleaving on impact parameters such as maximum load is negligible, but on the other hand could decrease damaged area significantly. By inserting $30 \mu \mathrm{m}$ of PCL nanofibers between each layer of laminate the damaged area decreased about $27 \%$.
\end{abstract}

C 2015 Growing Science Ltd. All rights reserved.

\section{Introduction}

Compared with more traditional materials such as metals and ceramics, fiber reinforced composites have several specific features such as high stiffness and strength to weight ratio. The most common failure mode of this high performance laminated material is delamination as a consequence of low velocity impact. Insufficient fracture toughness and delamination are the main issues affecting the longterm reliability of thermosetting matrix composites. Matrix-toughening seems to be one of the recommended methods, in which interleaf layers of toughened materials are inserted into the middle plies of the composites. Generally, thermoplastic particles and films have been used as common toughened layers (Sohn et al., 2000). However, difficulty of particle preparation due to high toughness of thermoplastic and high thickness of films due to high viscosity of thermoplastic, have limited their uses in industrial applications. Recently, nanofibers reinforcing was known as a more useful technique instead of particles or films reinforcing to enhance the mechanical properties of composite because of their very small diameters.

* Corresponding author.

E-mail addresses: $\underline{\text { hamed.saghafi2@unibo.it }}$ (H. Saghafi)

C) 2015 Growing Science Ltd. All rights reserved. doi: $10.5267 /$ j.esm.2014.12.003 
Up to now various kinds of polymeric nanofibers have been applied for increasing fracture toughness of composite materials such as Polysulfone (PSF) (Li et al., 2008), Nylon 6 (De Schoenmaker et al., 2013), phenoxy (Magniez et al., 2011), Nylon 6,6 (Palazzetti et al., 2013,Saghafi et al., 2014; Alessi et al., 2014), poly( $\varepsilon$-caprolactone) (PCL) (Zhang et al., 2012), polyvinylidene fluoride (PVDF) (Magniez et al., 2010) and etc. PCL is a suitable choice for toughening epoxy which its effect on mode-I fracture toughness was considered by Zhang et al. (2012). Since there is no study regarding the effect of PCL nanofibers under impact loading of interleaved composite laminates, in this study this behaviour is investigated.

\section{Experimental program}

\subsection{Electrospinning method}

Electrospinning is a process that utilizes electrostatic force to spin fibers from a polymeric solution. PCL were dissolved in Formic acid/Acetic acid $(60: 40 \mathrm{v} / \mathrm{v})$ and the resulting solution transferred to a syringe fitted with a fine needle. The details about this process can be found in (Van Der Schueren et al. 2011). The diameter of nanofibers is about $300 \mathrm{~nm}$ and the final thickness of nanofibrous mat is about $30 \mu \mathrm{m}$. Fig. 1 shows the morphology of PCL nanofibers.

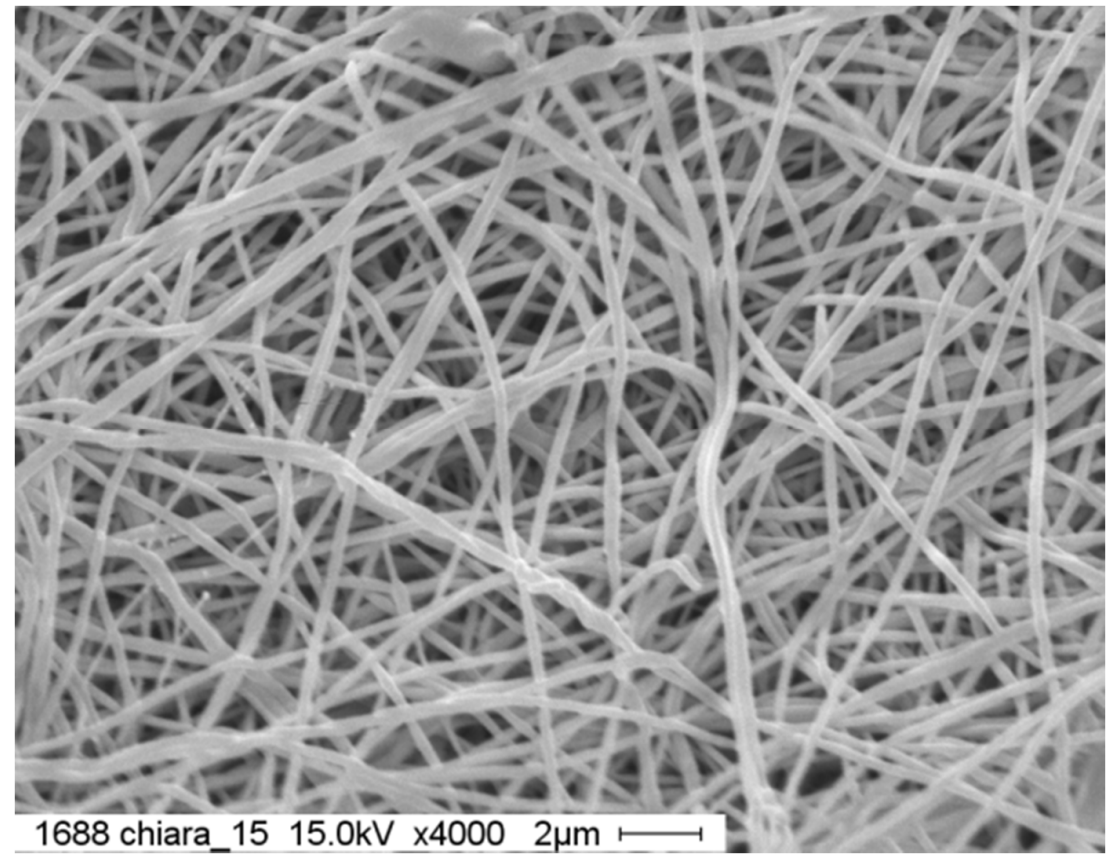

Fig. 1. The morphology of PCL nanofibers

\subsection{Sample preparation}

Glass fiber/epoxy prepreg was kindly supplied by Metal T.I.G. Company. Nine laminates of $[0 / 90 / 0 / 90]_{S}$ stacking sequence was used for fabricating impact test panels. Interleaved panels were made by placing one layer of polymer nanofabric between two consecutive prepregs except between the middle layers where two $90^{\circ}$-layers are on each other. Then, test panels were cured by using a vacuum bag in an autoclave under $150^{\circ} \mathrm{C}$ and for about 1 hour (according to supplier's suggestion). The specimens were then curved to obtain the dimensions shown in Fig. 2. It is worth mentioning that the effect of nanofibers on the final thickness of the specimen is less than $1 \%$. 


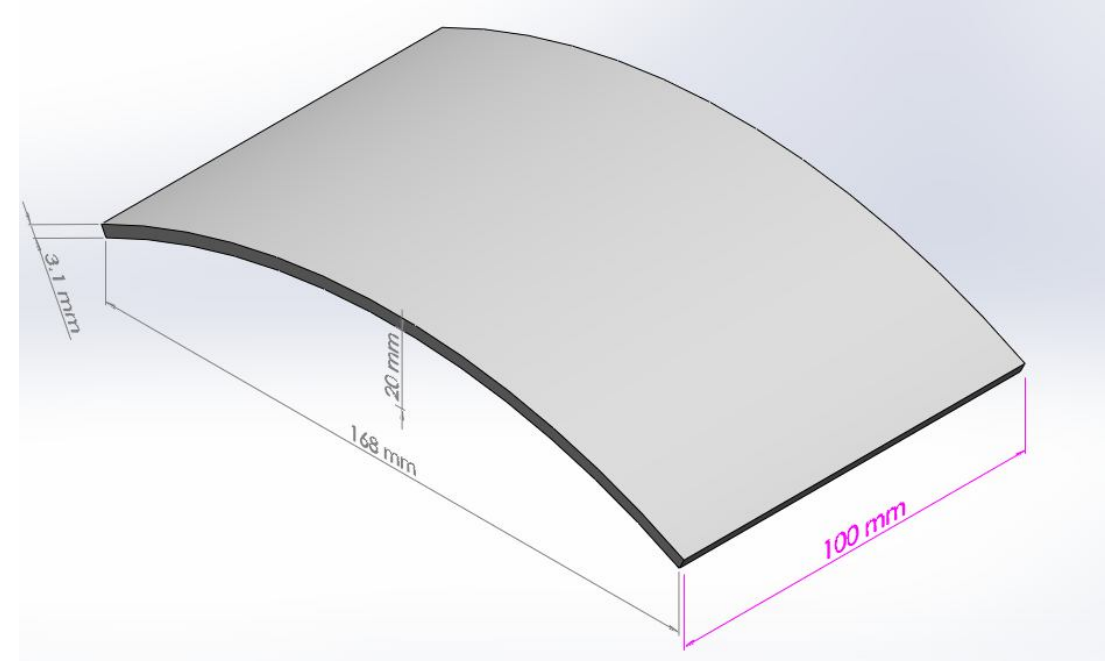

Fig. 2. Schematic picture of the curved laminate

\subsection{Impact tests}

Low velocity impact tests were conducted in a drop-weight machine equipped with a laser device for determining the position of impactor. A piezoelectric load cell was on the tip of the impactor for measuring the contact force during impact. The impactor was a steel spherical ball having a diameter of $12.7 \mathrm{~mm}$ and total mass of impactor was $1.22 \mathrm{~kg}$. The impact tests were conducted under energies of 24 and $36 \mathrm{~J}$ and three tests were performed for each configuration.

\section{Results and discussion}

In this section the effect of PCL nanofiber interleaved between GFRP layers on the impact characteristics, such as peak load $\left(\mathrm{P}_{\max }\right)$, contact duration $\left(\mathrm{t}_{0}\right)$, maximum deflection $\left(\mathrm{X}_{\max }\right)$, and damage area are examined against the corresponding impact energy of 24 and 36J. Fig. 3 represents impact force versus time and displacement for the reference and interleaved GFRP specimens.

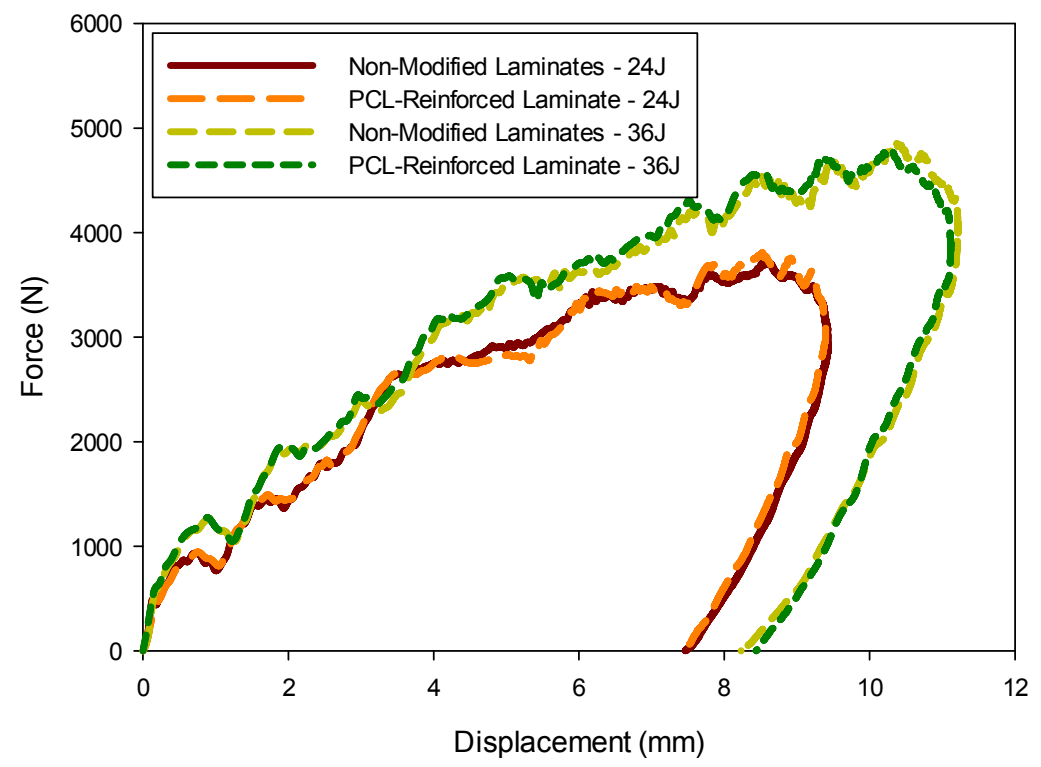

Fig. 3. Impact response of plain and interleaved GFRP laminates 
As seen from Fig. 3, the maximum load and maximum displacement of reference and interleaved laminates have the same behaviour under impact loading. According to the curves in both impact energies the trend of curves for both kinds of samples is also very similar. So it can be concluded that total impact energy is almost equal for reference and modified laminates. On the other hand according to the picture shown in Fig. 4, the damaged area is less in modified laminates. Therefore, less delamination in the modified laminates is because of the energy absorbed by PCL. The effect of PCL nanofibers has been considered before by Zhang et al. (2012). During curing process PCL nanofibers were changed to spherical particles for more uniformly dispersion in the continuous matrix (i.e. phase separation) as shown in Fig. 5. The increase of toughness is completely related to this separated phase. Because stress concentration caused by particles produces initiation of shear bands which form plastic zones and hence more energy is absorbed during loading.

Table 1 presents the damaged area values caused by impact loads. It is seen from this Table that, by applying PCL nanofibers the damaged area decreases about $26.5 \%$ and $24.2 \%$ under impact loads of 24 and $36 \mathrm{~J}$, respectively.

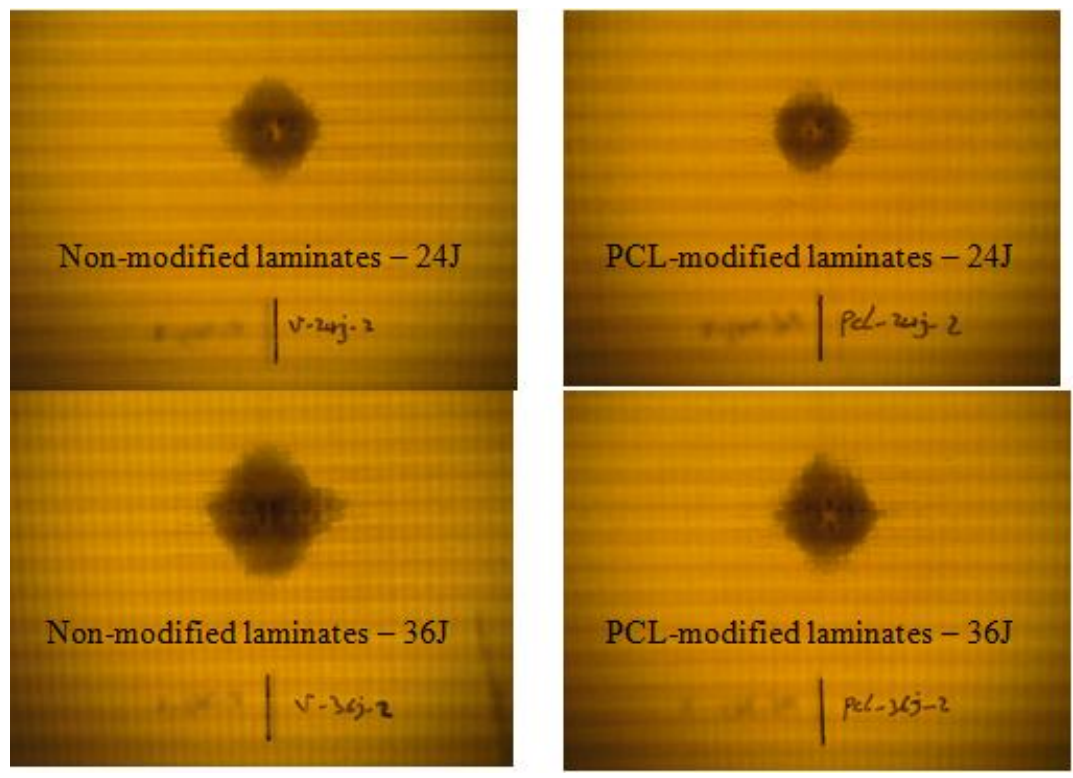

Fig. 4. Damaged area under different impact energies

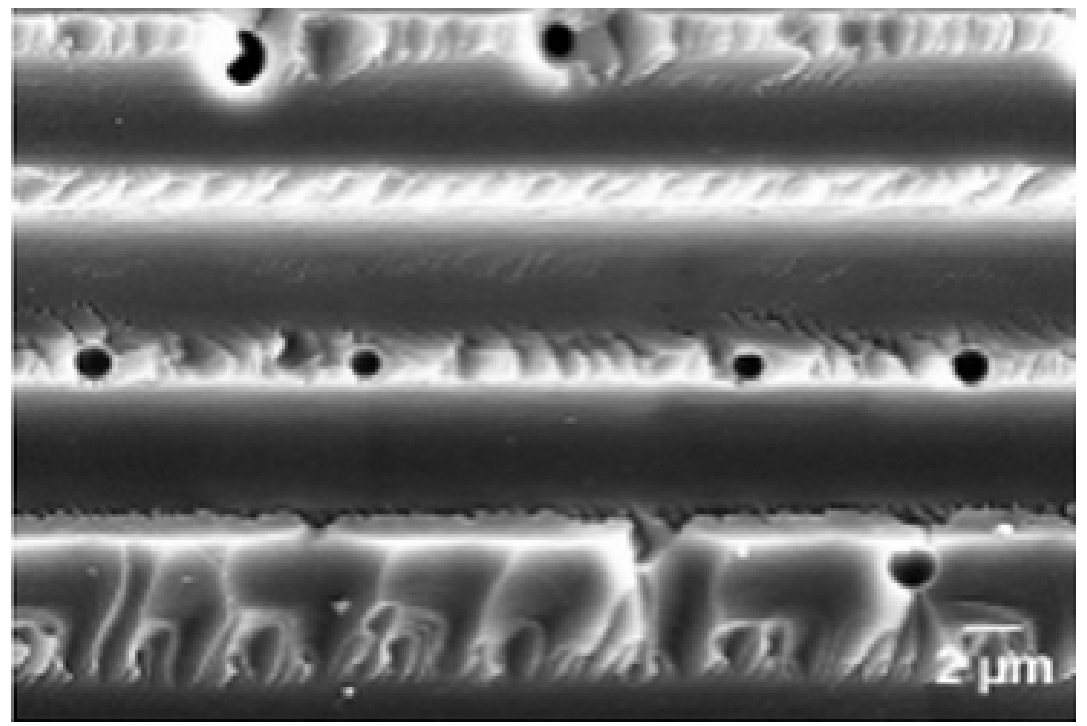

Fig. 5. PCL particles dispersed in the matrix (Zhang et al. 2012) 
Table 1. Damaged area sizes (in $\mathrm{mm}^{2}$ ) for modified and non-modified laminates subjected to different impact loads

\begin{tabular}{llll}
\hline Impact load $(\mathrm{J})$ & $\begin{array}{l}\text { Damage area }\left(\mathrm{mm}^{2}\right) \\
\text { For non-modified } \\
\text { laminates }\end{array}$ & $\begin{array}{l}\text { For PCL-modified } \\
\text { laminates }\end{array}$ & $\begin{array}{l}\text { Deference between } \\
\text { modified and non- } \\
\text { modified (\%) }\end{array}$ \\
\hline 24J & 170 & 125 & 26.5 \\
36J & 260 & 197 & 24.2 \\
\hline
\end{tabular}

\section{Conclusion}

In this research, PCL nanofibers were used for toughening composite laminates and its effect on low-velocity-impact parameters such as damaged area and maximum force was considered. The results showed that this toughening method has significant effect on the reduction of the damaged area such that up to $26 \%$ reduction of damage zone size was observed when the PCL nanofibers were used in the construction of composite laminates.

\section{Acknowledgement}

The authors would like to thank the annonymous referees for constructive comments on earliver verion of this paper.

\section{References}

Alessi, S., Di Filippo, M., Dispenza, C., Focarete, M. L., Gualandi, C., Palazzetti, R., Pitarresi, G \& Zucchelli, A. (2014). Effects of Nylon 6, 6 nanofibrous mats on thermal properties and delamination behavior of high performance CFRP laminates. Polymer Composites.

De Schoenmaker, B., Van der Heijden, S., De Baere, I., Van Paepegem, W., \& De Clerck, K. (2013). Effect of electrospun polyamide 6 nanofibres on the mechanical properties of a glass fibre/epoxy composite. Polymer Testing,32(8), 1495-1501.

Li, G., Li, P., Zhang, C., Yu, Y., Liu, H., Zhang, S., ... \& Ryu, S. (2008). Inhomogeneous toughening of carbon fiber/epoxy composite using electrospun polysulfone nanofibrous membranes by in situ phase separation. Composites Science and Technology, 68(3), 987-994.

Magniez, K., De Lavigne, C., \& Fox, B. L. (2010). The effects of molecular weight and polymorphism on the fracture and thermo-mechanical properties of a carbon-fibre composite modified by electrospun poly (vinylidene fluoride) membranes. Polymer, 51(12), 2585-2596.

Magniez, K., Chaffraix, T., \& Fox, B. (2011). Toughening of a carbon-fibre composite using electrospun poly (hydroxyether of bisphenol a) nanofibrous membranes through inverse phase separation and inter-domain etherification.Materials, 4(11), 1967-1984.

Palazzetti, R., Zucchelli, A., \& Trendafilova, I. (2013). The self-reinforcing effect of Nylon 6,6 nanofibres on CFRP laminates subjected to low velocity impact. Composite Structures, 106, 661-671.

Saghafi, H., Zucchelli, A., Palazzetti, R., \& Minak, G. (2014). The effect of interleaved composite nanofibrous mats on delamination behavior of polymeric composite materials. Composite Structures, 109, 41-47.

Saghafi, H., Minak, G. \& Zucchelli, A. (2014). The Effect of Pre-stress on Impact Response of Concave and Convex Composite Laminates A. Composites Part B: Engineering, 60, 74-81.

Sohn, M. S., Hu, X. Z., Kim, J. K., \& Walker, L. (2000). Impact damage characterisation of carbon fibre/epoxy composites with multi-layer reinforcement. Composites Part B: Engineering, 31(8), 681-691. 
Van der Schueren, L., De Schoenmaker, B., Kalaoglu, Ö. I., \& De Clerck, K. (2011). An alternative solvent system for the steady state electrospinning of polycaprolactone. European Polymer Journal, 47(6), 1256-1263.

Zhang, J., Yang, T., Lin, T., \& Wang, C. H. (2012). Phase morphology of nanofibre interlayers: Critical factor for toughening carbon/epoxy composites. Composites science and technology, 72(2), 256262. 